\title{
Cycling Stability of Li-ion Batteries at Elevated Temperature
}

Guangjin Zhao ${ }^{1,2}, \mathrm{Fei} \mathrm{Xu}^{3, *}$

${ }^{1}$ State Grid Henan Electric Power Research Institute, No.85, Songshan South Road, Zhengzhou, Henan, 450052, China

${ }^{2}$ Laboratory for Grid Waste Treatment and Resource Recycle Technology, State Grid Corporation of China, Zhengzhou, Henan, 450052, China

${ }^{3}$ School of Power and Mechanical Engineering, Wuhan University, Wuhan 430072, China

*E-mail: xufei2058@whu.edu.cn

doi: $10.20964 / 2018.09 .58$

Received: 8 May 2018 / Accepted: 3 July 2018 / Published: 5 August 2018

Cycling stability of commercial Li-ion batteries (LIBs) at elevated temperature is investigated in the present study. Galvanostatic discharge/charge cycling demonstrates that LIB shows a much faster capacity fading at $60{ }^{\circ} \mathrm{C}$ with a low capacity retention rate of $47 \%$ after 100 cycles, in contrast to the value of $97 \%$ at $25{ }^{\circ} \mathrm{C}$. Electrochemical impedance spectroscopy indicates that the internal resistance shows a much faster increase at $60^{\circ} \mathrm{C}$ than at $25^{\circ} \mathrm{C}$. Further scanning electron microscopy observation suggests that the increase of resistance is mainly originated from the thickening of the solid electrolyte interface on the anode surface. These results indicate that temperature has a significant effect on the performance of LIBs, and operation of LIBs at elevated temperature should be provented.

Keywords: Li-ion batteries; cycling stability; temperature; impedance; scanning electron microscopy

\section{FULL TEXT}

(C) 2018 The Authors. Published by ESG (www.electrochemsci.org). This article is an open access article distributed under the terms and conditions of the Creative Commons Attribution license (http://creativecommons.org/licenses/by/4.0/). 